\title{
PREPARAÇÃO E PROPRIEDADES DE ZEÓLITAS FAUJASITA CONTENDO CÁTIONS AMÔNIO
}

\author{
Karina Arruda Almeida, Leandro Martins e Dilson Cardoso* \\ Departamento de Engenharia Química, Universidade Federal de São Carlos, CP 676, 13560-970 São Carlos - SP, Brasil
}

Recebido em 29/7/09; aceito em 20/1/10; publicado na web em 3/5/10

\begin{abstract}
PREPARATION AND PROPERTIES OF FAUJASITE ZEOLITES CONTAINING AMMONIUM CATIONS. Sodium faujasite zeolites with $\mathrm{Si} / \mathrm{Al}$ ratio of 1.4 and 2.5 were exchanged with methylammonium cations. The influence of framework aluminum and ion exchange degree in their basic properties were evaluated. These properties were assessed in the Knoevenagel catalytic condensation. The sodium ion exchange was restricted to the supercavity and the exchange degree depended on the cation volume and on the $\mathrm{Si} / \mathrm{Al}$ ratio. The higher catalytic activity is achieved for the zeolite with the lower $\mathrm{Si} / \mathrm{Al}$ ratio exchanged with the monomethylammonium cation. The best performance of this catalyst is attributed to the higher basicity in combination with elevated micropore volume.
\end{abstract}

Keywords: faujasite zeólitas; basic catalyst; methylammonium cations.

\section{INTRODUÇÃO}

Do ponto de vista ambiental, os processos que envolvem a química fina estão entre os mais poluidores. Estas indústrias geram aproximadamente 10 vezes mais resíduos por massa de produto que as indústrias de grande escala, como o refino de petróleo. ${ }^{1}$ A grande quantidade de resíduo é gerada porque a maioria dos processos envolve reações em fase homogênea. Neste aspecto, os catalisadores sólidos, entre eles as zeólitas, são uma alternativa para minimização do problema, pois o seu uso diminui as operações de neutralização e separação, o que leva a uma redução significativa do volume de efluentes químicos.

A troca iônica com cátions inorgânicos para gerar a basicidade em zeólitas tem sido a forma mais estudada. ${ }^{2,3}$ No entanto, segundo alguns autores, ${ }^{2,4}$ o estudo de zeólitas como catalisadores básicos não tem sido muito comum devido à dificuldade na caracterização dos sítios ativos.

Na década de 1960, Theng e Barrer ${ }^{5,6}$ estudaram as isotermas de troca iônica de cátions alquilamônio nas zeólitas faujasita, denominadas comercialmente de $\mathrm{X}$ e $\mathrm{Y}$, entretanto as propriedades destes materiais não foram avaliadas. Apenas em 2007, Martins et al. ${ }^{7}$ reportaram o uso da zeólita $\mathrm{Y}$ (razão $\mathrm{Si} / \mathrm{Al}=2,5$ ) contendo cátions metilamônio como catalisadores básicos na condensação de Knoevenagel. Em comparação com zeólita Y contendo o césio, cátion que gerava os sítios básicos mais fortes conhecidos até então, esses materiais híbridos forneceram conversões muito superiores na condensação do benzaldeído com cianoacetato de etila. ${ }^{7}$

A basicidade das zeólitas é devido à presença de tetraedros de $\left[\mathrm{AlO}_{4}\right]^{-o u}\left[\mathrm{SiO}_{4}\right] \cdot{ }^{3,7}$ Os sítios básicos estão associados aos átomos de oxigênio estruturais próximos aos cátions compensadores de cargas. ${ }^{3}$ As propriedades ácido-base em zeólitas podem ser classificadas de acordo com o modelo de Lewis. Segundo este modelo, quando a força de um caráter aumenta a do outro diminui. Assim, quanto menor a acidez do cátion de compensação de cargas negativas maior a basicidade gerada pelo ânion oxigênio. Quando o cátion de compensação é pouco eletronegativo a densidade de carga do oxigênio pode ser grande o suficiente para gerar propriedades básicas. ${ }^{3}$ No caso dos alumino-silicatos, quanto maior o número e a concentração de átomos de alumínio, maior a força básica dos átomos de oxigênio. ${ }^{3}$

Assim, dando continuidade a nossos trabalhos anteriores ${ }^{7-9} \mathrm{o}$ objetivo deste trabalho foi avaliar a influência da razão $\mathrm{Si} / \mathrm{Al}$ nas propriedades de faujasitas trocadas com cátions metilamônio. A

*e-mail: dilson@ufscar.br reação modelo de condensação de Knoevenagel foi utilizada para avaliar a basicidade destas zeólitas.

\section{PARTE EXPERIMENTAL}

\section{Obtenção das isotermas de troca iônica}

Na preparação dos catalisadores foram utilizadas zeólitas comerciais X e Y com razão $\mathrm{Si} / \mathrm{Al}$ iguais a 1,4 e 2,5, respectivamente. As isotermas de troca iônica foram obtidas a $40{ }^{\circ} \mathrm{C}$, através do procedimento descrito em trabalho anterior. ${ }^{7}$ Foram utilizados os seguintes sais para preparação da solução de troca: cloreto de amônio $\left(\mathrm{NH}_{4} \mathrm{Cl}\right.$ - Synth, $\left.98 \%\right)$, cloreto de metilamônio e trimetilamônio $\left(\mathrm{NH}_{3} \mathrm{CH}_{3}{ }^{+} \mathrm{Cl}\right.$ e NH$\left(\mathrm{CH}_{3}\right)_{3}{ }^{+} \mathrm{Cl}$ - Fluka, $\left.98 \%\right)$ e cloreto de tetrametilamônio $\left(\mathrm{N}\left(\mathrm{CH}_{3}\right)_{4}^{+} \mathrm{Cl}\right.$, Aldrich, $\left.98 \%\right)$.

A concentração total de cátions foi mantida constante em 0,05 $\mathrm{mol} / \mathrm{L}$, por adição da quantidade de $\mathrm{NaCl}$ necessária, complementando a de cátion orgânico, que foi variada. A massa de zeólita empregada resultou numa proporção de cátions totais $\left(\mathrm{C}^{+}+\mathrm{Na}^{+}\right) / \mathrm{Al}$ iguais a $4 \mathrm{e}$ 6, respectivamente, para as zeólitas X e Y. Para a obtenção dos pontos de máxima troca iônica foram realizadas três trocas consecutivas com solução do cátion orgânico correspondente a uma concentração de $0,5 \mathrm{~mol} / \mathrm{L}$. A Tabela 1 mostra a nomenclatura adotada para os catalisadores de acordo com o cátion orgânico e zeólitas empregadas.

Tabela 1. Nomenclatura das amostras

\begin{tabular}{lcc}
\hline Cátion & Zeólita X & Zeólita Y \\
\hline $\mathrm{Na}^{+}$ & $\mathrm{NaX}$ & $\mathrm{NaY}$ \\
$\mathrm{NH}_{4}^{+}$ & $\mathrm{NH}_{4} \mathrm{X}$ & $\mathrm{NH}_{4} \mathrm{Y}$ \\
$\mathrm{CH}_{3} \mathrm{NH}_{3}^{+}$ & $\mathrm{Me}_{1} \mathrm{X}$ & $\mathrm{Me}_{1} \mathrm{Y}$ \\
$\left(\mathrm{CH}_{3}\right)_{3} \mathrm{NH}^{+}$ & $\mathrm{Me}_{3} \mathrm{X}$ & $\mathrm{Me}_{3} \mathrm{Y}$ \\
$\left(\mathrm{CH}_{3}\right)_{4} \mathrm{~N}^{+}$ & $\mathrm{Me}_{4} \mathrm{X}$ & $\mathrm{Me}_{4} \mathrm{Y}$ \\
\hline
\end{tabular}

\section{Caracterização}

A concentração de sódio e alumínio nas zeólitas foi determinada por espectrometria de emissão atômica por plasma indutivamente acoplado (ICP-OES).

As medidas de termogravimetria foram realizadas em um equipamento da TA Instruments (SDT 2960), empregando-se uma taxa de aquecimento de $10{ }^{\circ} \mathrm{C} / \mathrm{min}$ e uma vazão de $\mathrm{N}_{2}$ de $40 \mathrm{~mL} / \mathrm{min}$. 
Os difratogramas de raios $\mathrm{X}$ das zeólitas, obtidas após a troca iônica, foram obtidos em um difratômetro Shimadzu XRD-6000 utilizando radiação $\mathrm{CuK} \alpha(40 \mathrm{kV}, 40 \mathrm{~mA})$, um filtro de níquel e velocidade do goniômetro de $0,5 \%$ min. Para a determinação do parâmetro cúbico de cela unitária $\left(\mathrm{a}_{0}\right)$, utilizou-se $15 \%$ em massa de silício elementar como padrão interno misturado fisicamente com a amostra previamente hidratada por $24 \mathrm{~h}$ em atmosfera saturada por solução concentrada de $\mathrm{CaCl}_{2}$. Os parâmetros de cela unitária $\left(\mathrm{a}_{0}\right)$ foram determinados através do programa UnitCel, ${ }^{10}$ utilizando os picos referentes à reflexão dos planos (220), (311), (331), (440), (533), (642) e (664).

As amostras foram caracterizadas por fisissorção de nitrogênio, realizadas na sua temperatura de ebulição, usando-se um equipamento da ASAP2020 Micromeritics. Para eliminar a água fisissorvida, as amostras foram previamente tratadas a $110^{\circ} \mathrm{C}$ e pressão de 0,1 $\mathrm{mmHg}$ por $2 \mathrm{~h}$. $\mathrm{O}$ volume específico de microporos foi determinado utilizando-se o método t-plot. ${ }^{11}$

A reação de condensação de Knoevenagel (Esquema 1) foi realizada em reatores batelada de $1 \mathrm{~mL}$, sob agitação, a $60^{\circ} \mathrm{C}$ por 1 h. Para estes ensaios foi preparada uma mistura reacional contendo quantidades equimolares $(4,8 \mathrm{mmol})$ de butiraldeído (Reagente 1 ) e cianoacetato de etila (Reagente 2), empregando 3\% em massa de catalisador. O produto da reação foi analisado em um cromatógrafo da Varian com coluna capilar DB-1 e detector de ionização por chama.

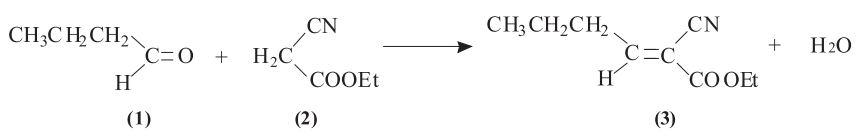

Esquema 1. Reação de condensação de Knoevenagel

\section{RESULTADOS E DISCUSSÃO}

\section{Isotermas de troca iônica}

A Figura 1 mostra as isotermas de troca iônica dos cátions sódio, presentes nas faujasitas $\mathrm{X}$ e $\mathrm{Y}$, por amônio, metil-, tri- e tetrametilamônio a $40{ }^{\circ} \mathrm{C}$. $\mathrm{O}$ eixo das abscissas representa a porcentagem molar desses cátions amônio, contendo grupos metila ou não, em equilíbrio $\left(\mathrm{S}_{\mathrm{E}}\right)$ na solução aquosa, e o eixo das ordenadas a porcentagem molar desses cátions amônio em equilíbrio na zeólita $\left(\mathrm{Z}_{\mathrm{E}}\right)$. As curvas e símbolos preenchidos referem-se à zeólita $\mathrm{X}$ e as curvas tracejadas e símbolos abertos à zeólita Y. Em todas as isotermas observa-se que, mesmo quando a solução aquosa contém praticamente só os cátions amônio em equilíbrio com o sólido $\left(\mathrm{S}_{\mathrm{E}}\right.$ $\cong 100$ ), a porcentagem desse cátion na zeólita é sempre menor que $80 \%\left(\mathrm{Z}_{\mathrm{E}}<80\right)$. Ou seja, nenhum dos cátions amônio consegue trocar todos os cátions sódio contidos na zeólita. Conforme Bre$\mathrm{ck},{ }^{12}$ a temperaturas próximas à ambiente, a troca iônica é limitada devido à inacessibilidade dos cátions presentes na solução aos prismas hexagonais e às cavidades sodalita. Consequentemente, nessas condições, a troca iônica se restringe às supercavidades. Além disso, quando os cátions são volumosos, como é o caso dos cátions amônio aqui estudados, a troca iônica também é limitada pela curta distância entre sítios trocáveis vizinhos, dificultando a acomodação dos cátions. ${ }^{7}$ De fato, a Figura 1 mostra que, à medida que aumenta o diâmetro dos cátions, há uma diminuição do máximo grau de troca, de aproximadamente 75 para $30 \%$. Adicionalmente, na Figura 1 verifica-se que, para os cátions mais volumosos (tri- e tetrametilamônio), o grau de troca é menor na zeólita $\mathrm{X}$ que na $\mathrm{Y}$, mostrando que também o teor de alumínio e, portanto, a distância entre eles na rede zeolítica, influi no grau máximo de troca. Este fator é conhecido por impedimento estérico dos cátions..$^{5-7}$
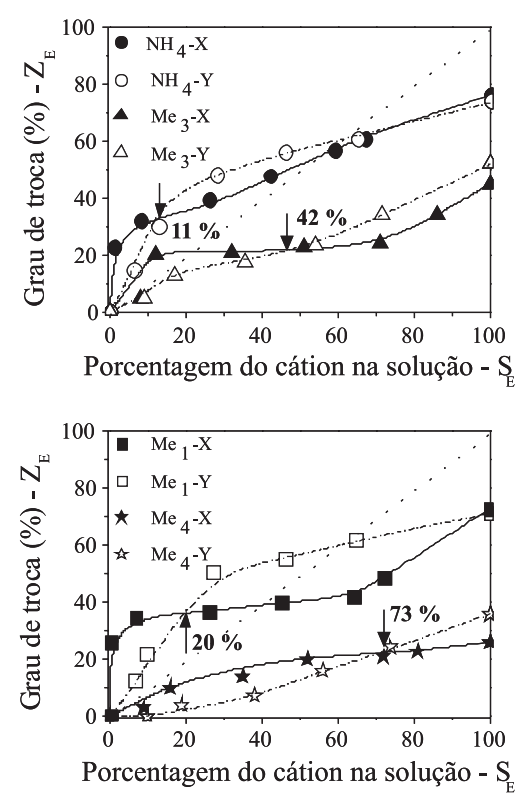

Figura 1. Isotermas de troca iônica para as zeólitas X e Y

No entanto, para baixas porcentagens dos cátions amônio na fase aquosa $\left(\mathrm{S}_{\mathrm{E}}\right)$, onde as trocas iônicas ainda ocorrem sem impedimento estérico, verifica-se que a porcentagem desses cátions é maior na zeólita $X$ do que na zeólita Y (Figura 1). Isso ocorre porque a zeólita $\mathrm{X}$ tem maior teor de alumínio. Logo, sua superfície é mais carregada negativamente, por isso esta zeólita tem maior afinidade pelos cátions amônio.

As isotermas de troca iônica dos pares iônicos $\mathrm{Na}-\mathrm{NH}_{4} \mathrm{X}, \mathrm{Na}-$ $\mathrm{NH}_{4} \mathrm{Y}, \mathrm{Na}-\mathrm{Me}_{1} \mathrm{Y}$ e Na-Me $\mathrm{X}$ apresentam perfil do tipo Langmuir,, 13 ou seja, muitos pontos acima da diagonal (linha tracejada $Z_{E}=S_{E}$ ), indicando que estas zeólitas são seletivas ao cátion trocador e, também, que existe uma forte interação entre o cátion e a superfície zeolítica. ${ }^{7,13}$

Os pares iônicos $\mathrm{Na}-\mathrm{Me}_{3} \mathrm{Y}$ e $\mathrm{Na}-\mathrm{Me}_{4} \mathrm{Y}$ apresentam isotermas não seletivas, indicando baixa interação dos cátions com a rede zeolítica. ${ }^{13}$ Este perfil é típico de troca iônica com cátions volumosos. ${ }^{7}$

Os pares $\mathrm{Na}-\mathrm{Me}_{1} \mathrm{X}$ e $\mathrm{Na}-\mathrm{Me}_{3} \mathrm{X}$ apresentam isotermas do tipo sigmoide que cruzam a diagonal em $\mathrm{S}_{\mathrm{E}} \cong 40$ e $\mathrm{S}_{\mathrm{E}} \cong 20$, respectivamente. Este perfil mostra que a seletividade é reversa em função de $\mathrm{Z}_{\mathrm{E}}$, até essas concentrações a zeólita apresenta seletividade moderada aos cátions trocadores. ${ }^{14} \mathrm{O}$ ponto de inflexão indica que os cátions podem ocupar mais de um tipo de sítios de troca e, que a seletividade é diferente para cada sítio. ${ }^{13,14}$

Os cátions sódio na cela unitária das faujasitas estão distribuídos em três tipos de sítios cristalográficos (I, II e III, Figura 1S, material suplementar). ${ }^{13,15}$ Os sítios I pertencem aos prismas hexagonais que interconectam as cavidades sodalita; os sítios II pertencem aos prismas hexagonais da cavidade sodalita que estão voltados para supercavidade e os sítios III pertencem à supercavidade próximos aos anéis de quatro membros da cavidade sodalita.

Na cela unitária da zeólita X, os sítios dos tipos II e III correspondem a 37 e $43 \%$ do total dos sítios existentes. ${ }^{12}$ Segundo Sherry, ${ }^{16}$ a troca iônica ocorre primeiro nos sítios III, depois nos sítios II, e finalmente nos sítios I, o que está de acordo com os resultados apresentados neste trabalho. Observa-se ainda na Figura 1 que no intervalo $20 \leq \mathrm{S}_{\mathrm{E}} \leq 70$ se tem grau de troca aproximadamente igual a $37 \%$ para a zeólita $\mathrm{Me}_{1} \mathrm{X}$, indicando que até essa concentração apenas os sítios tipo III, os mais acessíveis, são trocados. $\mathrm{O}$ cátion trimetilamônio troca apenas $20 \%$ dos cátions sódio até $\mathrm{S}_{\mathrm{E}} \cong 70$ e $45 \%$ quando $S_{E} \cong 100$. Portanto, apenas parte dos sítios II são trocados pelo cátion trimetilamônio. 
Como já citado, as zeólitas Y e X apresentam, para o cátion metilamônio, isotermas do tipo Langmuir e sigmoide, respectivamente. Essa diferença no perfil ocorre porque na zeólita X ocorre competição entre os sítios II e III. ${ }^{16} \mathrm{Na}$ zeólita Y essa competição não ocorre, pois apenas $14 \%$ dos sítios são do tipo III, enquanto $56 \%$ são do tipo II. Portanto, a zeólita $\mathrm{X}$ tem três vezes mais sítios do tipo III que a zeólita Y, e por isso a isoterma desta última não apresenta ponto de inflexão, típico de troca iônica com competição. ${ }^{13}$

\section{Termogravimetria}

Os termogramas para as zeólitas $\mathrm{NaY}$ e $\mathrm{NaX}$ (Figura 2S, material suplementar) apresentaram apenas um pico intenso entre 25 e $340^{\circ} \mathrm{C}$, relativo à perda de água fisissorvida e de hidratação dos cátions sódio, cuja interação é mais forte. Na zeólita $\mathrm{NaY}$ a máxima velocidade de perda de água ocorre a $150{ }^{\circ} \mathrm{C}$ e na $\mathrm{NaX}$ em $140{ }^{\circ} \mathrm{C}$. De acordo com a teoria de Eisenman, quanto maior a razão $\mathrm{Si} / \mathrm{Al}$ menor a interação do sódio com a estrutura. ${ }^{13,17}$ Consequentemente, maior é a sua energia de hidratação, por isso a zeólita NaY necessita de uma temperatura maior para a dessorção da água. Além disso, a zeólita $\mathrm{NaX}$ por ter maior teor de sódio perde aproximadamente $5 \%$ mais água que a $\mathrm{NaY}$.

A Figura 2 mostra os termogramas e suas derivadas para as zeólitas $\mathrm{X}$ e Y contendo os máximos graus de troca dos cátions amônio e mono-, tri- e tetrametilamônio. Estes gráficos podem ser divididos em três regiões de perda de massa. A região 1 , entre 25 e $220^{\circ} \mathrm{C}$, corresponde à dessorção da água fisissorvida e de hidratação dos cátions. Esta faixa de temperatura diminui em relação às zeólitas na forma sódica, indicando menor interação da água com estes cátions mais volumosos. As máximas velocidades de dessorção da água mostradas na Figura 2 ocorrem em torno de 150 e $110{ }^{\circ} \mathrm{C}$, respectivamente, para as zeólitas X e Y. Para as zeólitas com cátions amônio ocorre inversão em comparação com as zeólitas sódicas: as zeólitas X têm velocidades máximas de perda de água em temperaturas maiores (150 contra $110^{\circ} \mathrm{C}$ para zeólitas Y).

Ainda na região 1 para as zeólitas NaX observa-se a separação dos picos de perda de água (Figura $2 b$ ) em pelo menos duas etapas. A difusão da água nos poros da zeólita durante esta etapa de secagem pode promover esta diferenciação.

A região 2, ocorrendo entre 250 e $550{ }^{\circ} \mathrm{C}$, corresponde à decomposição dos cátions amônio e metilamônio. ${ }^{18}$ As velocidades máximas de decomposição ocorrem em torno de $490^{\circ} \mathrm{C}$. Comparando as velocidades de decomposição da região 2 (Figura 2 b) observa-se que para zeólita $\mathrm{Y}$ os picos em torno de $490^{\circ} \mathrm{C}$ são bem mais definidos e que existe um pequeno sinal próximo a $250{ }^{\circ} \mathrm{C}$, que não aparece nos termogramas da zeólita $\mathrm{X}$.

Na região 3 , acima de $550{ }^{\circ} \mathrm{C}$ ocorre perda de massa devido à desidroxilação das faujasitas, ${ }^{18}$ cuja hidroxila é formada pelo próton resultante da decomposição dos cátions amônio e metilamônio. Os picos são bem definidos apenas para a zeólita Y. A zeólita X é menos estável devido a sua maior carga aniônica e, provavelmente as reações de decomposição do cátion e de desidroxilação ocorram simultaneamente, mascarando os picos de sua desidroxilação. ${ }^{19,20}$ Para a zeólita Y observa-se que a temperatura em que ocorre a máxima velocidade de desidroxilação aumenta com o volume do cátion. Isso ocorre porque com o aumento do volume do cátion a troca iônica ocorre entre sítios mais distantes, dificultando a reação.

\section{Difração de raios-X}

A zeólita X tem mais alumínio de rede que a zeólita Y, ou seja, a fração molar de Al é igual a 0,43 e 0,29, respectivamente, para as zeólitas X e Y. Como o comprimento da ligação Al-O é maior que o da ligação $\mathrm{Si}-\mathrm{O}$, os parâmetros de cela $\left(\mathrm{a}_{0}\right)$ da zeólita $\mathrm{X}$ são maiores que
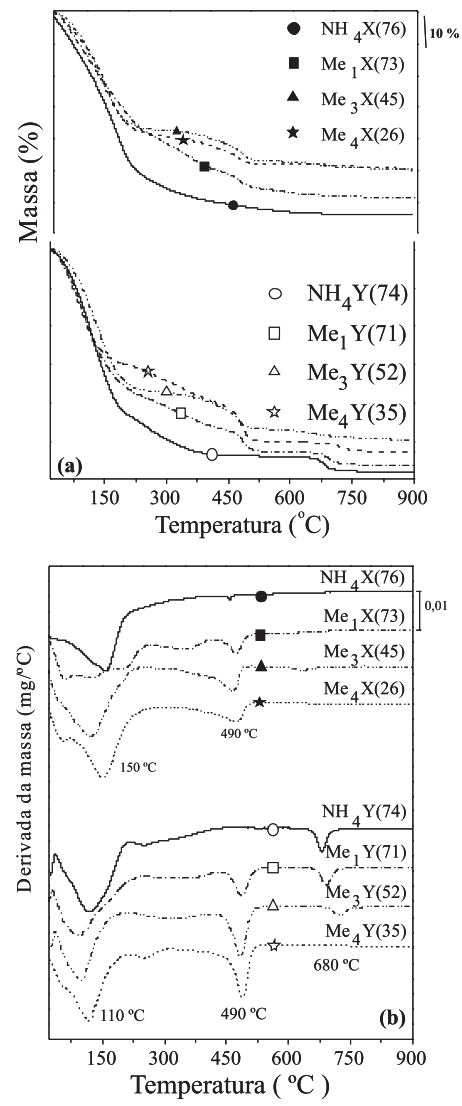

Figura 2. Termogramas e suas derivadas para as zeólitas X e Y contendo os máximos graus de troca iônica (indicados entre parênteses)

os da zeólitas Y, como pode ser visto na Tabela 2. Ainda nesta tabela, observa-se que tanto para a zeólita $\mathrm{X}$ como para a $\mathrm{Y}$ os valores de $\mathrm{a}_{0}$ aumentam com o volume do cátion, concordando com os resultados de Martins et al. ${ }^{7}$ Ao contrário do esperado, a zeólita $\mathrm{Me}_{4} \mathrm{X}$ apresenta um parâmetro de cela menor que o da zeólita $\mathrm{Me}_{3} \mathrm{X}$. Este comportamento se deve a impedimentos estéricos, considerando a maior proximidade dos ânions na rede zeolítica, o que faz com que o máximo grau de troca com o cátion tetrametilamônio seja menor $\left(Z_{E}=26 \%\right)$.

Tabela 2. Parâmetros cela unitária das zeólitas contendo sódio e os máximos graus de troca dos cátions metilamônio

\begin{tabular}{lccccc}
\hline $\begin{array}{l}\text { Zeólita X } \\
(\mathrm{Si} / \mathrm{Al}=1,3)\end{array}$ & $\mathrm{Z}_{\mathrm{E}}(\%)$ & $\mathrm{a}_{0}(\mathrm{~nm})$ & $\begin{array}{c}\text { Zeólita } \mathrm{Y} \\
(\mathrm{Si} / \mathrm{Al}=2,5)\end{array}$ & $\mathrm{Z}_{\mathrm{E}}(\%)$ & $\mathrm{a}_{0}(\mathrm{~nm})$ \\
\hline $\mathrm{NaX}$ & 0 & 2,5002 & $\mathrm{NaY}$ & 0 & 2,4695 \\
$\mathrm{NH}_{4} \mathrm{X}$ & 76 & 2,5009 & $\mathrm{NH}_{4} \mathrm{Y}$ & 74 & 2,4697 \\
$\mathrm{Me}_{1} \mathrm{X}$ & 73 & 2,5055 & $\mathrm{Me}_{1} \mathrm{Y}$ & 71 & 2,4698 \\
$\mathrm{Me}_{3} \mathrm{X}$ & 45 & 2,5115 & $\mathrm{Me}_{3} \mathrm{Y}$ & 52 & 2,4713 \\
$\mathrm{Me}_{4} \mathrm{X}$ & 26 & 2,5071 & $\mathrm{Me}_{4} \mathrm{Y}$ & 35 & 2,4738 \\
\hline
\end{tabular}

\section{Volume de microporos}

A Figura 3 mostra os volumes de microporos das zeólitas Y e X medidos através das isotermas de adsorção de nitrogênio, em função do grau de troca do cátion sódio pelos cátions amônio. Como se observa na Figura 3, no caso da zeólita Y, o volume de microporos diminui linearmente com o aumento do grau de troca, evidenciando que o espaço ocupado pelos cátions amônio é proporcional ao seu teor na zeólita. Nessa figura observa-se ainda que, para um mesmo grau de troca, o volume dos microporos diminui com o aumento do raio do cátion amônio. No entanto, deve ser levado em consideração que 
o parâmetro de cela unitária aumenta com o raio do cátion (Tabela 2). Portanto, o comportamento do volume de microporos é resultado de dois fatores: um que diminui o volume disponível, a substituição de cátion de menor raio iônico por cátion de maior raio; e outro que o aumenta o volume disponível, o aumento do parâmetro da cela unitária.

O comportamento do volume de microporos na zeólita X, em função do grau de troca, apresenta várias diferenças em comparação ao da zeólita Y. Como se observa na Figura 3, nas zeólitas de partida (ou seja, zero\% de grau de troca) o volume de microporos da zeólita $\mathrm{X}$ na forma sódica é $0,278 \mathrm{~cm}^{3} / \mathrm{g}$, enquanto que na zeólita Y correspondente é de $0,250 \mathrm{~cm}^{3} / \mathrm{g}$. Essa redução de cerca de $10 \%$ na zeólita $\mathrm{NaY}$ se deve ao menor comprimento ${ }^{4}$ da ligação Si-O em relação à ligação Al-O. Como o teor de silício na zeólita Y é maior que na X, isso causa uma redução no parâmetro da cela unitária (Tabela 2) e, consequentemente, no volume de microporos.

Outra diferença entre as duas zeólitas está na variação do volume de microporos: enquanto na zeólita Y ele decresce linearmente com o grau de troca, na zeólita $\mathrm{X}$ esse comportamento é mais complexo. $\mathrm{Na}$ Figura 3 vemos que, para baixos graus de troca (menores que 20\%) o volume de microporos praticamente não se altera, independentemente do raio do cátion amônio. A partir desse valor, no caso dos cátions orgânicos, o volume de microporos decresce com o aumento do grau de troca e do raio do cátion, comportamento similar ao da zeólita Y.

Aparentemente, o efeito da presença dos cátions orgânicos é mais pronunciado na zeólita $\mathrm{Y}$, pois seu volume mínimo de microporos atinge valores próximos a $0,10 \mathrm{~cm}^{3} / \mathrm{g}$, enquanto o volume mínimo de microporos na zeólita $X$ é reduzido a $0,21 \mathrm{~cm}^{3} / \mathrm{g}$. Essa diferença ocorre devido ao volume de microporos da zeólita inicial, $\mathrm{NaX}$, ser maior que o da NaY. No entanto, estimativas realizadas em iguais condições de quantidade de cátions revelam que a diminuição do valor do volume de microporos é similar em ambas zeólitas.

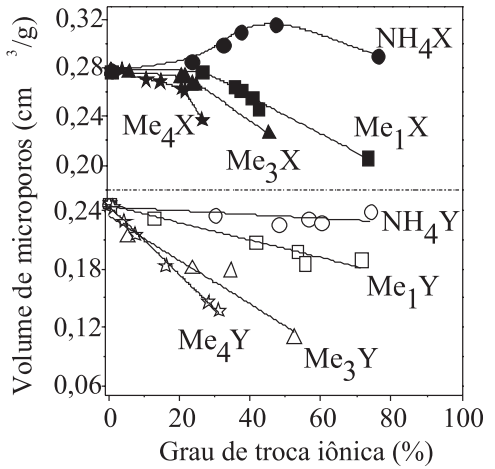

Figura 3. Volume de microporos em função do grau de troca das zeólitas X e Y

Finalmente, no caso da zeólita X amoniacal, a relação entre volume de microporos e grau de troca é bastante inesperada, pois a curva passa por um máximo, resultados que foram reprodutíveis. $\mathrm{O}$ valor do raio dos cátions hidratados pode explicar a diferença nesse comportamento. Como mostra a Tabela 3, o raio iônico hidratado do cátion amônio é cerca de $8 \%$ menor do que o do cátion sódio hidratado. Por isso, na zeólita $X$ o volume de microporos aumenta até $Z_{\mathrm{E}} \cong 50$.

Tabela 3. Valores dos raios iônico não hidratado e hidratado dos cátions sódio e amônio ${ }^{5,21}$

\begin{tabular}{lcc}
\hline Cátion & Raio iônio $(\mathrm{nm})$ & Raio hidratado $(\mathrm{nm})$ \\
\hline $\mathrm{Na}^{+}$ & 0,095 & 0,358 \\
$\mathrm{NH}_{4}^{+}$ & 0,148 & 0,331 \\
$\mathrm{Me}_{1}^{+}$ & 0,245 & -- \\
$\mathrm{Me}_{3}^{+}$ & 0,320 & -- \\
$\mathrm{Me}_{4}^{+}$ & 0,347 & 0,367 \\
\hline
\end{tabular}

\section{Condensação de Knoevenagel}

A Figura 4 mostra a conversão do n-butiraldeído, na condensação de Knoevenagel com cianoacetato de etila, em função do grau de troca dos cátions sódio das zeólitas X e Y com amônio e metilamônio. Nas condições de reação utilizadas neste trabalho, a seletividade da reação de condensação de Knoevenagel, formando o composto 3 da Reação 1, foi sempre de $100 \%$. Na Figura 4 observa-se também que os catalisadores preparados com a zeólita $\mathrm{X}$ alcançam conversões sempre superiores àquelas obtidas com os catalisadores preparados com a zeólita Y. Por exemplo, a zeólita $\mathrm{Me}_{1} \mathrm{X}$, com grau de troca igual a $50 \%$, atinge uma conversão de $80 \%$, que é 10 vezes maior que a zeólita $\mathrm{Me}_{1} \mathrm{Y}$. A maior atividade dos catalisadores se deve ao maior teor de alumínio na rede da zeólita $\mathrm{X}$ e, quanto maior esse teor, maior o número e a força dos sítios catalíticos com propriedades básicas. ${ }^{22,23}$

Os resultados mostram também que, para todos os cátions orgânicos, aumentando o grau de troca do cátion sódio, aumenta a conversão, sugerindo que o aumento da basicidade, decorrente da troca iônica, supera a redução do volume de microporos mostrada na Figura 3. Essa tendência também foi observada por Martins et al. ${ }^{7}$ na condensação de Knoevenagel com a zeólita Y como catalisador, usando o benzaldeído como componente carbonílico, um composto mais volumoso que o butiraldeído.

Estudos de Martins et al. ${ }^{7,23}$ utilizando a zeólita Y e o benzaldeído nesta mesma reação mostraram que, para um mesmo grau de troca, a conversão aumenta com o volume do cátion trocador, pois é nesta sequência que aumenta a basicidade do sítio catalítico. Porém, esse comportamento não foi observado na zeólita X. Por exemplo, para grau de troca igual a 30\% a atividade da zeólita $X$ aumenta do cátion amônio para o monometilamônio, mas diminui ao se passar para o trimetilamônio e mais ainda para o tetrametilamônio. Essa passagem por um máximo de conversão, ao se aumentar o raio do cátion pode ser explicada pelo fato da zeólita $\mathrm{X}$ ter maior teor de alumínio na rede e, consequentemente, maior quantidade de cátions de compensação. Ao se aumentar o raio do cátion, no caso da zeólita $\mathrm{X}$, eles passam a dificultar a entrada dos reagentes restringindo, portanto, o seu acesso aos sítios catalíticos. A zeólita Y, ao contrário, tem menor número de cátions e, assim, a difusão dos reagentes e produtos pelos poros é mais fácil e, por isso a conversão para esta zeólita aumenta continuamente com o volume do cátion de compensação.
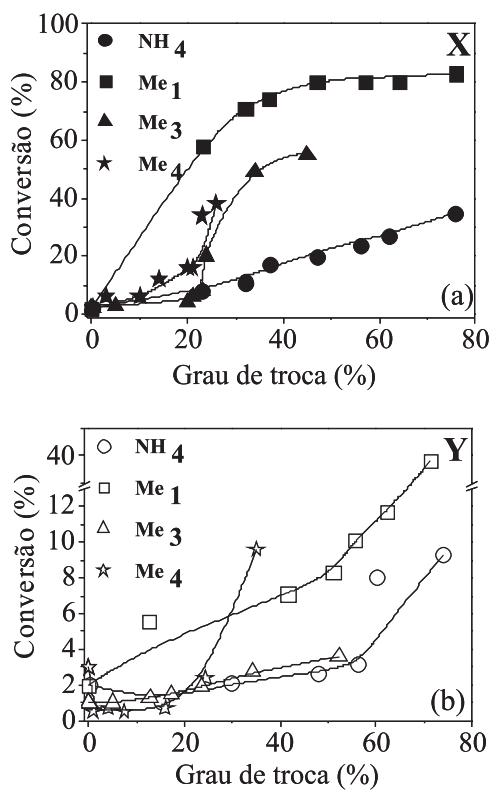

Figura 4. Conversão do n-butiraldeído em função do grau de troca na condensação de Knoevenagel 


\section{CONCLUSÕES}

A troca dos cátions sódio por amônio e metilamônio restringe-se às supercavidades, pois a abertura das cavidades sodalita e os prismas hexagonais impedem a troca iônica no interior dessas cavidades. Dependendo do número de grupos metila pertencentes ao cátion orgânico, efeitos estéricos impedem que nem todos os sítios pertencentes às supercavidades sejam trocados. Devido ao maior número de sítios básicos, a zeólita $\mathrm{X}$ contendo cátions amônio é muito mais ativa na condensação de Knoevenagel que a zeólita Y, sendo o fator limitante para o avanço da reação a inacessibilidade dos reagentes aos sítios catalíticos. Nas condições de reação utilizadas, a zeólita $\mathrm{Me}_{1} \mathrm{X}$ é o catalisador mais ativo para a condensação de Knoevenagel entre o n-butiraldeído e cianoacetato de etila.

\section{MATERIAL SUPLEMENTAR}

No material suplementar, disponível gratuitamente em http:// quimicanova.sbq.org.br na forma de arquivo PDF, estão contidas informações sobre a localização dos sítios de troca na faujasita (Figura $1 \mathrm{~S}$ ) e termogramas das zeólitas $\mathrm{X}$ e Y na forma sódica (Figura $2 \mathrm{~S}$ ).

\section{AGRADECIMENTOS}

À Capes e FAPESP pelo apoio financeiro.

\section{REFERÊNCIAS}

1. Guinest, M.; Ramôa, F. R.; Zeólitos: Um Nanomundo da Catálise, Ed. FCG: Lisboa, 2004
2. Hattori, P. E.; Chem. Rev. 1995, 88, 42.

3. Martins, L.; Cardoso, D.; Quim. Nova 2006, 29, 358.

4. Barthomeuf, D.; Micropor. Mesopor. Mater. 2003, 66, 1.

5. Theng, B. K. G.; Vansant, E.; Uytterhoeven, J. B.; Trans. Far. Soc. 1968, 64, 3370 .

6. Barrer, R. M.; Papadopoulos, R.; Rees, L. V. C.; J. Inor. Nuclear Chem. 1967, 29, 2047.

7. Martins, L.; Boldo, R. T.; Cardoso, D.; Micropor. Mesopor. Mater. 2007, 98, 166.

8. Martins, L.; Vieira, K. M.; Rios, L. M.; Cardoso, D.; Catal. Today 2008, 133-135, 706

9. Oliveira, A. C.; Martins, L.; Cardoso, D.; Micropor. Mesopor. Mater. 2009, 120, 206.

10. Holland, T. J. B.; Redefern, S. A. T.; Mineralogical Magazine 1997, 61, 65.

11. Lippens, B. C.; De Bôer, J. H.; J. Catal. 1965, 4, 319.

12. Breck, D. W.; Zeolite Molecular Sieves, John Wiley: New York, 1974.

13. Colella, C.; Miner. Dep. 1996, 31, 554.

14. Pansini, M.; Collela, C.; Caputo, D.; Gennaro, M.; Langella, A.; Micropor. Mater. 1996, 5, 357.

15. Olson, D. H.; Zeolites 1995, 15, 439.

16. Sherry, H.; J. Phys. Chem. 1996, 70, 1158.

17. Mortier, W. J.; J. Catal. 1978, 55, 138.

18. Kresnawahjuesa, O.; Olson, D. H.; Gorte, R. J.; Kühl, G. H.; Micropor. Mesopor. Mater. 2002, 51, 175.

19. Pochen, C.; Francis, G. D.; J. Catal. 1980, 61, 452.

20. Hickson, D. A.; Csicsery, S. M.; J. Catal. 1968, 10, 27.

21. Nightingale, E. R.; J. Phys. Chem. 1959, 63, 1381.

22. Barthomeuf, D.; Catal. Rev. Sci. Eng. 1996, 38, 521.

23. Martins L.; Holderich, W.; Cardoso, D.; J. Catal., 2008, 258, 14 


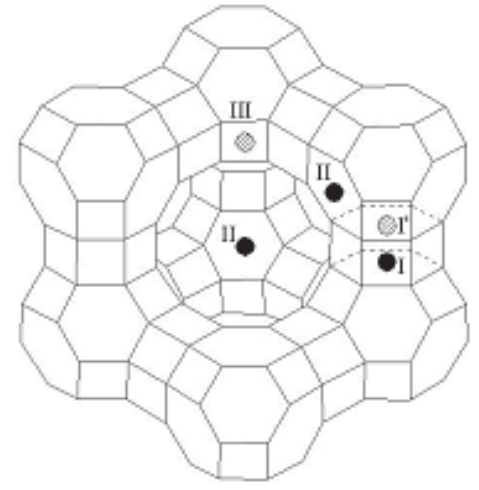

Figura 1S. Localização dos sítios de troca na faujasita

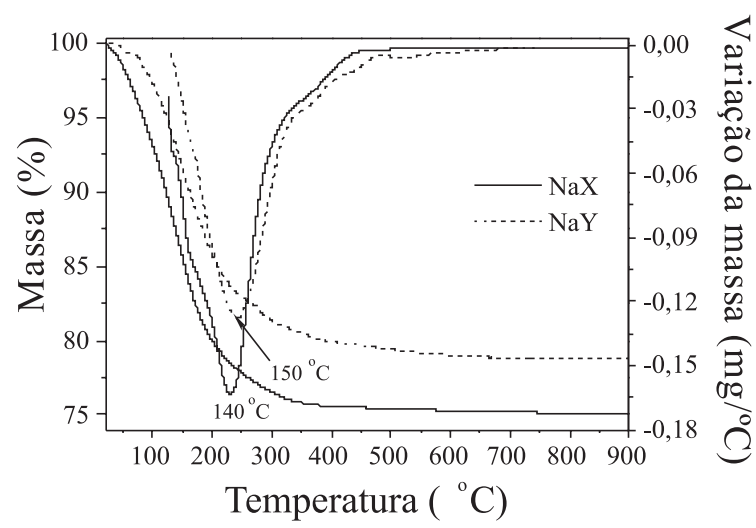

Figura 2S. Termogramas das zeólitas X e Y na forma sódica 